(2) Open Access Full Text Article

\title{
Acute macular edema following intracorporeal prostaglandin injection for erectile dysfunction
}

This article was published in the following Dove Press journal:

International Medical Case Reports Journal

22 July 2015

Number of times this article has been viewed

\section{Masumi G Asahi \\ Calvin Chou \\ Ron P Gallemore \\ Retina Macula Institute, Torrance, CA, USA}

\begin{abstract}
Purpose: We aimed to describe the first case of macular edema following intracorporeal injection of alprostadil, a prostaglandin E1.

Methods: This was a retrospective case report followed with optical coherence tomography, fundus photos, and fluorescein angiography images.

Results: A patient developed bilateral cystoid macular edema following intracorporeal injection of alprostadil, a prostaglandin E1 for treatment of erectile dysfunction. The edema resolved following treatment with nonsteroidal anti-inflammatory drugs (NSAIDs) and corticosteroids, with subsequent recovery in visual acuity.

Discussion: Systemic prostaglandin administration can cause macular edema and vision loss, indicating that elevated systemic prostaglandin levels may affect visual function. This has potential implications for other systemic disorders and treatments that could affect macular function.
\end{abstract}

Keywords: alprostadil, inflammation

\section{Introduction}

Cystoid macular edema (CME) is associated with inflammatory mediators in the posterior segment of the eye, most commonly prostaglandin E2 (PGE2). ${ }^{1}$ Macular edema (ME) has been identified as a common cause of decreased vision in many ophthalmic disorders, including retinal vein occlusion, uveitis, and diabetic retinopathy. Recently we observed a patient who developed acute $\mathrm{CME}$ in both eyes following intracorporeal injection of prostaglandin for erectile dysfunction.

\section{Methods}

A retrospective chart review was performed on a patient who presented to the Retina Macula Institute (Torrance, CA, USA) with vision loss following an intracorporeal alprostadil injection. ME and response to treatment was monitored with fluorescein angiography (FA) and macular optical coherence tomography (OCT) measurements using spectral domain OCT (SD-OCT), on the Cirrus HD-OCT (Carl Zeiss Meditec AG, Jena, Germany).

\section{Case report}

An 82-year-old pseudophakic male complained of acute vision loss in both eyes (OU) 1 week following intracorporeal injection of alprostadil for erectile dysfunction. The patient used a $20 \mu \mathrm{g}$ strength injector to deliver a dose of $20 \mu \mathrm{g}$ of alprostadil. Alprostadil was injected intracavernously into the lateral penis (corpus cavernosa) at
Correspondence: Ron P Gallemore 420I Torrance Boulevard,

Torrance, CA 90503, USA

Tel + I 3109449393

Fax + I 3109443393

Email rongallemoremd@gmail.com 
the recommended $90^{\circ}$ injection angle. A constriction band is normally not applied with application of alprostadil and was not applied in this case. The patient used the medication at the recommended frequency of maximum three times a week, and no other erectile dysfunction medications, such as phosphodiesterase type 5 (PDE5) inhibitors, were being used concurrently.

The patient reported engorgement of the penis following the injection, but developed subsequent vision loss and presented to our clinic within 72 hours. Serendipitously, he had been evaluated 1 week prior for monitoring of his nonexudative macular degeneration (MD) and mild ME associated with epiretinal membrane (ERM) OU (Figure 1A and B). He was deemed stable at the time, while being treated with topical loteprednol etabonate $0.5 \%$ and bromfenac ophthalmic solution $0.09 \%$ once daily (qd) OU for treatment of the ME. He was not using any systemic medications at this time. His vision dropped from 20/30 to 20/40 in the right eye (OD) and from 20/30 to 20/70 in the left eye (OS). Intraocular pressure was stable, at $15 \mathrm{mmHg}$ OD and $14 \mathrm{mmHg}$ OS before and $17 \mathrm{mmHg}$ OD and $16 \mathrm{mmHg}$ OS after the intracorporeal injection. He had a positive family history of MD and cataracts.

Anterior segment and external examination were unremarkable with no cells in the anterior chamber or anterior vitreous. The lens was pseudophakic OU. Dilated fundoscopy showed an ERM OS > OD and nonexudative MD OU. OCT studies revealed CME with an increase in central macular thickness of $17 \mu \mathrm{m}$ OD and $94 \mu \mathrm{m}$ OS (Figure 1C and D). FA studies showed no evidence of exudative conversion and revealed CME OU with optic nerve hyperfluorescence, OS $>$ OD (Figure 2A and B).

The patient underwent treatment with bromfenac $0.09 \%$ ophthalmic solution twice daily (BID) OU and difluprednate $0.05 \%$ BID OU. He then underwent vitrectomy OS for removal of the progressive ERM OS. The patient was also advised to discontinue the erectile dysfunction medication.

At 1 month following treatment with bromfenac OU and difluprednate OU, and 3 weeks following vitrectomy OS, the ME improved, with a decrease in central macular thickness of $11 \mu \mathrm{m}$ OD and $107 \mu \mathrm{m}$ OS. Vision remained stable at 20/40 OD but improved from 20/70 OS to 20/40 OS, with a stable intraocular pressure of $16 \mathrm{mmHg}$ OD and $15 \mathrm{mmHg}$ OS. The edema, however, was chronic OS and required further treatment, including alternating $0.5 \mathrm{cc}$ retrobulbar triamcinolone acetonide $(40 \mathrm{mg} / \mathrm{mL})$ injection and intravitreal dexamethasone implant $(0.7 \mathrm{mg})$ OS every 6-8 weeks over the next year. The patient was also continued on bromfenac $0.09 \%$ qd OU, and loteprednol etabonate $0.5 \%$ was varied from qd to BID OU over the course of the year. A 6-month follow-up revealed that central macular thickness decreased $65 \mu \mathrm{m} \mathrm{OD}$ and $34 \mu \mathrm{m}$ OS (Figure 1E and F). FA studies revealed resolution of active macular leakage, with no evidence of exudative MD 7 months following treatment (Figure 2C and D). Visual acuity ultimately recovered to 20/20 OD and 20/25 OS 1 year after vision loss.
OD
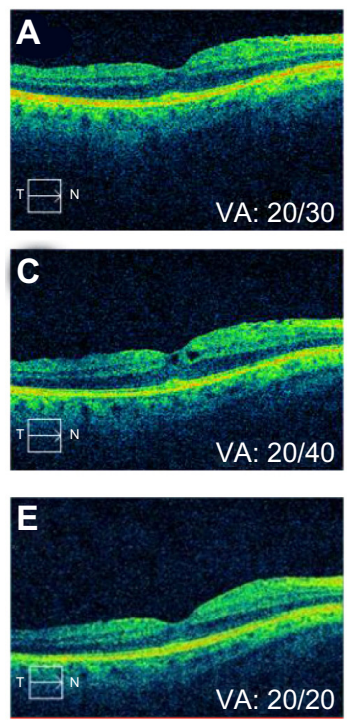
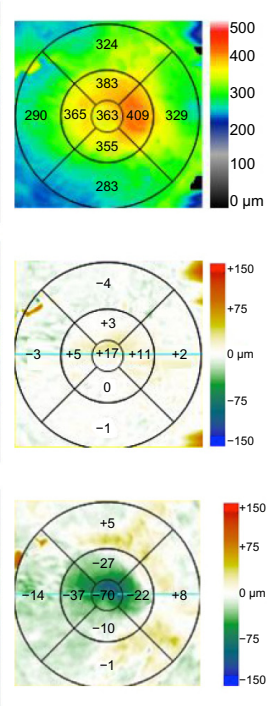

OS
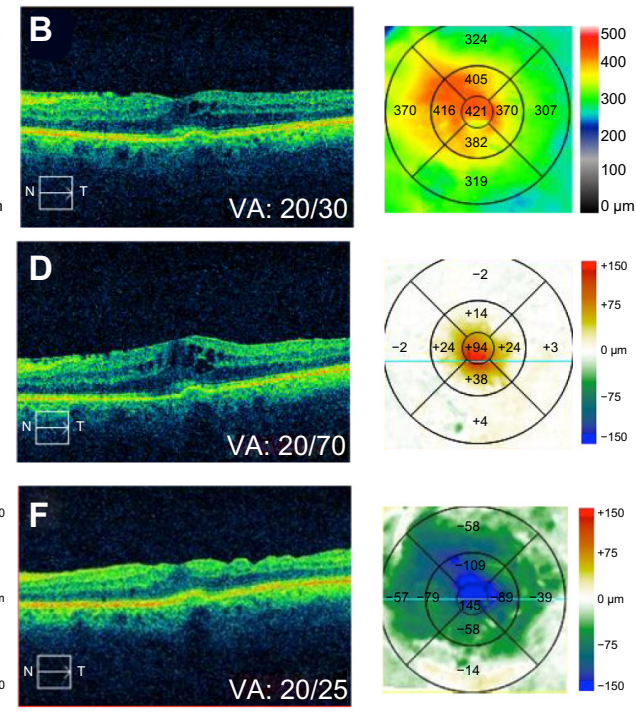

Figure I Baseline OCT and contour maps of right (A) and left (B) eyes at I week post-PGEI injection; OCT with difference map of right (C) and left (D) eyes; and posttreatment OCT with difference maps of right (E) and left (F) eyes.

Abbreviations: OCT, optical coherence tomography; OD, right eye; OS, left eye; PGEI, prostaglandin EI; VA, visual acuity. 


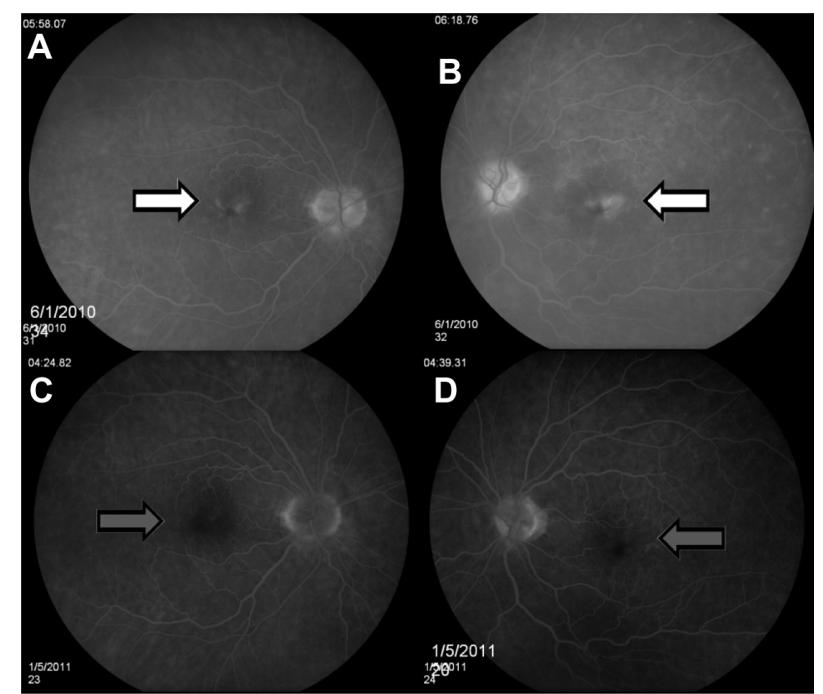

Figure 2 Fluorescein angiography I week following systemic injection of PGEI of right (A) and left (B) eyes, and following treatment of right (C) and left (D) eyes. Note: White arrows and gray arrows define the area of CME before and after treatment, respectively.

Abbreviations: CME, cystoid macular edema; PGEI, prostaglandin EI.

\section{Results and discussion}

Prostaglandins are known inflammatory mediators and have been determined to be a causative factor of CME, particularly in the setting of cataract surgery or with the use of prostaglandin analogs used for the treatment of glaucoma. ${ }^{1}$ Here, we report the first case of CME associated with systemic prostaglandin injection. This provides evidence that prostaglandins alone can precipitate this potentially blinding disorder. PGE2 is a known component of inflammatory fluids isolated from both the vitreous and other systemic locations in the setting of inflammatory disease. ${ }^{1}$ Prostaglandin E1 (PGE1), known pharmaceutically as alprostadil, is the active component found in the Food and Drug Administration (FDA)-approved injection treatments for erectile dysfunction. ${ }^{2}$ PGE1 has been shown to produce maximal inflammatory and vascular permeability effects comparable with PGE2 in animal models. ${ }^{3}$

In order for alprostadil to induce ME, the drug must cross the blood-brain barrier. Although this process is not fully understood, PGE1 has been shown to cross the blood-brain barrier, in an in situ rat brain perfusion technique. ${ }^{4}$ Furthermore, intravitreal injections of PGE1 in rabbit models have been shown to cause breakdown of the blood-retinal barrier (BRB) by opening tight junctions between vascular endothelial cells, which causes capillary leakage and ME. ${ }^{5}$ The above provide evidence that PGE1 from alprostadil crosses the blood-brain barrier and breaks down tight junctions in the BRB. The compromised tight junctions provide paracellular pathways for systemic prostaglandins, such as PGE2, and other inflammatory mediators to cross the BRB through the vascular endothelial cells and induce inflammation and subsequent ME. PGE1 has also been shown to act on retinal pigment epithelium (RPE) cell surface receptors to increase cyclic adenosine monophosphate (AMP), via adenylate cyclase, which can also cause marked disruption of the BRB.${ }^{6}$ Cyclic AMP has also been shown to inhibit fluid transport from the apical to basal surface of the RPE in isolated frog RPE-choroid preparations and to inhibit the resorption of subretinal fluid in rabbits. ${ }^{78}$ Antagonism of fluid transport and inhibition of fluid resorption by cyclic AMP can contribute to ME and further compromise the BRB.

There are confounding macular pathologies that likely made our patient more susceptible to ME following the PGE1 injection, such as the ERM and MD. The optic nerve hyperfluorescence on the FA studies argues against these etiologies alone causing the edema. ERM tangential traction is the likely cause of low-grade ME, and the ERM likely made the patient more susceptible to an exacerbation of ME by the PGE1 injection. The temporal relationship between the patient's vision loss and intracorporeal injection argue that the injection of prostaglandin itself was a primary contributing factor of the development of CME and subsequent vision loss.

Prostaglandins induce inflammation by binding to $\mathrm{G}$ protein-coupled prostaglandin receptors. They can also induce COX-1 and COX-2 activity, increasing endogenous prostaglandin levels, which can result in ME, in the pathway described above. ${ }^{9}$ Both nonsteroidal anti-inflammatory drugs (NSAIDs) and steroids act to inhibit COX-dependent prostaglandin production. NSAIDs act at the level of the COX enzymes and the glucocorticoids act at a more fundamental step in the cytokine pathway, at the level of phospholipase A2. ${ }^{9,10}$ Steroids and NSAIDs can act synergistically to treat CME. ${ }^{10}$ NSAIDs and corticosteroids are known to indirectly reduce permeability of choroidal endothelial cells and the outer BRB, thereby reducing ME. ${ }^{1}$ In this case, edema resolved following treatment with NSAIDs and glucocorticoid steroid medication.

Prescribers of alprostadil and other prostaglandin analogs for the treatment of erectile dysfunction should be aware of the patient's ocular health prior to prescribing these medications. Risk factors for prostaglandin-induced CME include ocular conditions that are considered to damage the blood-ocular barrier, such as ERM, ocular surgery, uveitis, or history of ME. ${ }^{11}$ Although prostaglandins have not been shown to induce CME in patients with a healthy blood-ocular 
barrier, caution should be taken as the incidence of CME in the healthy population is not clear. ${ }^{11,12}$

PDE5 inhibitors, such as sildenafil, are also widely prescribed for the treatment of erectile dysfunction. Although PDE5 inhibitors are generally considered to have a good ocular safety profile, there have been reports of ocular symptoms with the use of this class of medication. This includes a blue tinge to vision and photophobia, serous macular detachment, third nerve palsies, and nonarteritic anterior ischemic optic neuropathy; however, a causal relationship has not been established between PDE5 inhibitors and the aforementioned ocular dysfunctions. ${ }^{13}$ Given the findings presented in this case and the risks of ocular dysfunction associated with the more commonly prescribed PDE5 inhibitors, patients considering treatment for erectile dysfunction are advised to obtain an ophthalmological consult to assess ocular health prior to initiating treatment with prostaglandin analogs or PDE5 inhibitors.

\section{Conclusion}

We report the first case of systemic prostaglandin administration causing CME. Our data suggests that systemic disorders associated with elevated prostaglandins, in and of themselves, could affect ME through the process described above. This has potential implications for other disorders and treatments, which could affect macular function.

\section{Disclosure}

The authors report no conflicts of interest in this work.

\section{References}

1. Miyake K, Ibaraki N. Prostaglandins and cystoid macular edema. Surv Ophthalmol. 2002;47 Suppl 1:S203-S218.

2. Costa P, Potempa AJ. Intraurethral alprostadil for erectile dysfunction: a review of the literature. Drugs. 2012;72(17):2243-2254.

3. Gyires K, Knoll J. Inflammation and writhing syndrome inducing effect of PGE1, PGE2 and the inhibition of these actions. Pol J Pharmacol Pharm. 1975;27(3):257-264.

4. Taogoshi T, Nomura A, Murakami T, Nagai J, Takano M. Transport of prostaglandin E1 across the blood-brain barrier in rats. $J$ Pharm Pharmacol. 2005;57(1):61-66.

5. Vinores SA, Sen H, Campochiaro PA. An adenosine agonist and prostaglandin E1 cause breakdown of the blood-retinal barrier by opening tight junctions between vascular endothelial cells. Invest Ophthalmol Vis Sci. 1992;33(6):1870-1878.

6. Friedman Z, Hackett SF, Campochiaro PA. Characterization of adenylate cyclase in human retinal pigment epithelial cells in vitro. Exp Eye Res. 1987;44(4):471-479.

7. Miller SS, Hughes BA, Machen TE. Fluid transport across retinal pigment epithelium is inhibited by cyclic AMP. Proc Natl Acad Sci USA. 1982;79(6):2111-2115.

8. Marmor MF, NegiA. Pharmacologic modification of subretinal fluid absorption in the rabbit eye. Arch Ophthalmol. 1986;104(11):1674-1677.

9. Maldve RE, Kim Y, Muga SJ, Fischer SM. Prostaglandin E(2) regulation of cyclooxygenase expression in keratinocytes is mediated via cyclic nucleotide-linked prostaglandin receptors. J Lipid Res. 2000;41(6): 873-881.

10. Gallemore RP. NSAIDs in treatment of retinal disorders. Rev Ophthalmol. 2006;13:81-88.

11. Furuichi M, Chiba T, Abe K, et al. Cystoid macular edema associated with topical latanoprost in glaucomatous eyes with a normally functioning blood-ocular barrier. J Glaucoma. 2001;10(3):233-236.

12. Agange N, Mosaed S. Prostaglandin-induced cystoid macular edema following routine cataract extraction. J Ophthalmol. 2010;2010:690707.

13. Kerr NM, Danesh-Meyer HV. Phosphodiesterase inhibitors and the eye. Clin Experiment Ophthalmol. 2009;37(5):514-523.
International Medical Case Reports Journal

\section{Publish your work in this journal}

The International Medical Case Reports Journal is an international, peer-reviewed open-access journal publishing original case reports from all medical specialties. Previously unpublished medical posters are also accepted relating to any area of clinical or preclinical science. Submissions should not normally exceed 2,000 words or

\section{Dovepress}

4 published pages including figures, diagrams and references. The manuscript management system is completely online and includes a very quick and fair peer-review system, which is all easy to use. Visit $\mathrm{http}: / / \mathrm{www}$.dovepress.com/testimonials.php to read real quotes from published authors. 